\title{
Assessment of Health Effects Related to the Use of Biomass Fuel and Indoor Air Pollution in Kapkokwon Sub-Location, Bomet Country, Kenya
}

\author{
Taratisio Ndwiga, Robert M. Kei, Hellen Jepngetich, Kenneth Korrir \\ Department of Environment Health, School of Public, Moi University, Eldoret, Kenya \\ Email: taratisiondwiga@yahoo.com
}

Received 20 June 2014; revised 23 July 2014; accepted 8 August 2014

Copyright (C) 2014 by authors and Scientific Research Publishing Inc.

This work is licensed under the Creative Commons Attribution International License (CC BY). http://creativecommons.org/licenses/by/4.0/

(c) (i) Open Access

\section{Abstract}

Biomass Fuel (BMF) refers to burned plant or animal material; wood, charcoal, dung and crop residues which account for more than half of domestic energy in most developing countries and for as much as $\mathbf{9 5 \%}$ in low income countries. It is estimated that about 3 billion people in the world rely on biomass fuel for cooking, heating and lighting. The biomass fuel chain includes gathering, transportation, processing and combustion. These processes are predominantly managed by women where they work as gatherers, processors, carriers or transporters and also as end-users or cooks. Thus, they suffer health hazards at all stages of the biomass fuel chain. The main objective was to assess health effects related to the use of Biomass fuel and indoor air pollution in Kapkokwon Sub-location, Kericho County, Kenya from March to May, 2013. The study area was Kapkokwon sub location, Bomet County, Kenya. The study population was 202 households. Primary females of the household were the target group as they managed the biomass chain. A quantitative descriptive cross-sectional study design was adopted to assess the health effects associated to the use of biomass fuel and indoor air pollution. The research revealed that women suffer different type of physical ailments due to the biomass fuel chain. Physical exhaustion (86\%), neck aches $(78 \%)$, headaches $(34 \%)$, knee aches $(30 \%)$ and back aches $(16 \%)$ were reported as the principal health effects associated with the third stage of the biomass fuel chain. Irritation of the mucus membrane of the eyes, nose and throat $(100 \%)$, coughing $(100 \%)$, burns $(42 \%)$, shortness of breath $(38 \%)$ and exacerbation of asthma $(2 \%)$ were identified as principal health effects associated with the fourth stage of the biomass fuel chain (cooking). As a result of the detrimental impact of indoor air pollution (IAP) on health and mortality, many governments, non-governmental organization and international organizations should develop strategies aimed at reducing indoor air pollution. The strategies to include subsidization of cleaner fuel technologies, development, promotion and subsidization of improved cooking stoves, use of solar thermal cookers 
and solar hot water heaters, processing biomass fuel to make them cleaner, modifying user behavior and improved household design.

\title{
Keywords
}

\author{
Biomass Fuel, Biomass Fuel Chain, Indoor Air Pollution, Indoor Environment
}

\section{Introduction}

Biomass Fuel (BMF) refers to the burned plant or the animal material; wood, charcoal, dung and crop residues which account for more than half of domestic energy in most developing countries and for as much as 95\% in low income countries [1]. It is estimated that about 3 billion people in the world rely on the biomass fuel for cooking, heating and lighting [2]. In the African region, more than half a billion people, representing $78 \%$ of the African population, continue to rely on BMF for cooking and heating [3]. In Kenya, 68\% of the populations rely on BMF for cooking and heating and up to $95 \%$ of energy consumed in rural areas is in the form of wood, agriculture residue and animal waste [4]. The biomass fuel chain includes gathering, processing, transportation and combustion. These processes are predominantly managed by women where they work as gatherers, processors, carriers or transporters and also as end-users or cooks. Thus, they suffer health hazards at all stages of the biomass fuel chain.

Burning BMF on open fires and traditional stoves produces smoke with immense airborne emission as a result of their incomplete combustion. These air borne emissions comprise of particulate matter and dangerous compounds, such as carbon monoxide, benzene, styrene and formaldehyde [3]. Studies have revealed that airborne emissions from combustion of a single index of BMF (wood, crop and dung) are much higher than fossil fuels such as kerosene and liquid petroleum gas [5]. The airborne emission produced from combustion of BMF results to indoor air pollution especially in poorly ventilated households.

\section{Literature Review}

Indoor air pollution is responsible for more than 1.6 million deaths per year and 39 million DALYs (Disability-Adjusted Life Years) due to pneumonia, chronic respiratory disease and lung cancer. Other diseases and conditions associated with indoor air pollution include asthma, bronchitis, tuberculosis, cataracts, low birth weight and heart disease. According to the World Health Organization, in high mortality developing countries indoor air pollution causes approximately 3.7 percent of the overall disease burden, fourth in impact after malnutrition, unsafe sex, and lack of sanitation and safe water [3].

The majority of victims of exposure to indoor air pollution are women and children. In low-income homes, especially in rural areas and informal urban settlements, women often spend between 3 and 7 hours per day near a traditional open fire cooking meals, and in cold months may tend to stay near a fire for heat for a large part of the day. Young children are often carried on their mother's back or kept close to the warm hearth. Consequently, children spend many hours breathing indoor smoke during their first year of life when their developing [3].

Indoor air pollution more than doubles the risk of pneumonia and other acute lower respiratory infection (ALRI) and thus is responsible for more than 900,000 of 2 million annual deaths from pneumonia and other ALRI. Women exposed to indoor smoke are three times as likely to suffer from Chronic Obstructive Pulmonary Disease (COPD), such as chronic bronchitis, than women who cook and heat with electricity, gas and other cleaner fuels. Consequently, indoor air pollution is responsible for more than 700,000 out of 2.7 million global deaths due to COPD [3]. In a 1987 study, the USA environmental Protection Agency ranked indoor air pollution fourth in cancer risk among the 13 top environmental problems analyzed [5]. Globally one million people die from lung cancer annually and indoor air pollution is responsible for approximately $1.5 \%$ of these deaths. In the African region indoor air pollution is responsible for 41,000 deaths per year due to COPD and 350,000 deaths due to ALRI. More than one third of all child deaths causes by air pollution occur in the African continent [3].

Women are the main protagonist of the biomass fuel chain as they work as gatherers, processors, carriers or transporters and also as end-users or cooks [6]. Studies have described how the biomass fuel chain imposes hardship, stress and physical discomfort for women [7]. The greatest health impacts as a result of the biomass 
fuel chain have been documented to occur among the poorest population who rely on biomass as their main energy source [8]. In Kenya 68\% of the population rely on BMF for cooking and heating and up to 95\% of energy consumed in rural areas is in the form of wood, agriculture residue and animal waste [4]. Women in these households are subjected to the burden associated with the biomass fuel chain.

Cooking and heating homes with BMF creates high level of indoor smoke, especially if women use traditional open fires and there is no chimney or other source of inadequate ventilation. The smoke from indoor fires exposes families to harmful levels of gases, particles, and dangerous compounds, such as carbon monoxide, benzene, styrene and formaldehyde [3]. Research has also shown that the indoor levels of some pollutants such as carbon monoxide, benzene and formaldehyde range from 2 to 50 times higher than outdoor levels [9]-[11].

Air pollution is a significant cause of morbidity and mortality. The indoor environment can be much polluted with pollution levels of indoors higher than those outdoors, particularly so when there are combustion processes associated with cooking and heating [12]. Indoor air pollution has been linked to an increased risk of diseases such as tuberculosis (TB), lung cancer, ALRI, COPD, stroke and eye disease such as cataract [13]-[16].

Previous studies have linked indoor air pollution to an increased risk of diseases such as tuberculosis (TB), lung cancer, ALRI, COPD, stroke and eye disease such as cataract [13]-[16]. From evidence in health records at the Kericho District Hospital, respiratory tract infections (RTIs) is the most common disease among children over and under five years. The study area is predominantly rural thus the principal source of energy used for heating and cooking is BMF [2]. In addition, the main type of housing in the study area comprises of the traditional African and semi-permanent houses. These houses are characterized by poor ventilation as the lack chimneys to expel smoke from the open fires used for cooking and heating. Studies have linked ventilation, kitchen location, and permeability of roofs and walls to smoke exposure [17]. The main aim of the study was to assess health effects related to the use of Biomass fuel and indoor air pollution in Kapkokwon Sub-location, Bomet County, Kenya

Indoor air pollution (IAP) remains a large global health threat. One half of the world population, and up to 95\% in poor countries, continues to rely on solid fuels, including biomass fuels (wood, dung, agricultural residues) and coal, to meet their energy needs. Cooking and heating with solid fuels on open fires or on traditional stoves generates high levels of health-damaging pollutants, such as particulates and carbon monoxide. As women are primarily responsible for cooking, and as children often spend time with their mothers while they are engaged in cooking activities, women and young children are disproportionately affected. For example, the World Health Report [18] estimates that acute lower respiratory infection (ALRI) is one of the leading causes of child mortality in the world, accounting for up to $20 \%$ of fatalities among children under five, almost all of them in developing countries (IAP is thought to cause about one-third of ALRI cases). This makes solid fuels the second most important environmental cause of disease after contaminated waterborne diseases [19]) and the fourth most important cause of overall excess mortality in developing countries after malnutrition, unsafe sex, and waterborne diseases [19].

Despite the importance of this issue, social scientists have only recently become interested in IAP. [20] observe that the most comprehensive review on economic studies of health in the developing world [21] does not contain any reference to this problem. Furthermore, much of the existing evidence on the consequences of IAP presents serious shortcomings, as it is largely based on observational studies and may confuse the causal effect of IAP with the effects of the determinants to its exposure. Also troubling is the fact we have very little evidence on the impact of IAP exposure on economic outcomes, such as child school attendance and adult labor market productivity.

For those on the lower rungs, cooking with traditional solid fuels on open flames or traditional cooking stoves may result in exposure to extremely damaging toxic pollutants, resulting in some contexts in ambient concentrations of more than 10 times the permitted EPA level over a 24 hour period. For example, $\mathrm{PM}_{10}$ refers to particulate matter with a diameter of less than or equal to $10 \mu \mathrm{m}$; these particles are widely believed to pose the greatest health problems. The United States Environmental Protection Agency (EPA) standard for an acceptable annual 24-hour average of $\mathrm{PM}_{10}$ is $150 \mu \mathrm{g} / \mathrm{m}^{3}$, and they state that this level should not be exceeded more than once per year. In fact, $50 \mu \mathrm{g} / \mathrm{m}^{3}$ is the accepted norm for $\mathrm{PM}_{10}$ [22]. In contrast, [23] reports that mean 24-hour $\mathrm{PM}_{10}$ concentration in solid-fuel-using households in India sometimes exceeds $2000 \mu \mathrm{g} / \mathrm{m}^{3}$. WHO [15] found an average of $600 \mu \mathrm{g} / \mathrm{m}^{3}$ in Bangladesh, far outside the EPA guidelines. Similarly, a study of about 400 households in the provinces of Shaanxi, Hubei, and Zhejiang, China, were monitored for $\mathrm{PM}_{4}$, and it was found that most households exceed China's Indoor Air Quality Standards [24]. 
These ambient concentration readings alone could mask individuals' true exposure, as exposure may also vary with an individual's proximity to the stove during periods when the stove is in use. [15] and [25] used personal monitors with real-time monitoring in rural Kenya over a two-year period. These studies record peak concentrations greater than $50,000 \mu \mathrm{g} / \mathrm{m}^{3}$ in the immediate vicinity of the cooking fire, which suggests that women and children who congregate near cooking stoves are exposed to pollution levels unheard of in the developed world. [26] and [27] found similar results in India, with reported levels of $20,000 \mu \mathrm{g} / \mathrm{m}^{3}$ or more near the cooking location and with much lower concentrations of these toxins in the rest of the kitchen/other rooms in the household.

Many previous studies have failed to take into account the optimizing behavior of the household. In Bangladesh, [20] found that, within the household, women who cook exhibit greater symptoms of respiratory illness, as do the young children whom they supervise. They also find that the women who cook tend to be the women with the worst health endowments. They conclude that the household "shares" the burden of disease in an optimal way. This suggests that any health gain associated with the availability of a new stove will be mediated by the household's behavioral response (for example, how and by whom they are used). It also suggests that there may be other welfare gains to the families associated with the new stoves. Collecting good measures of individual time use and individual exposure to pollution for all household members before and after the introduction of a new technology is, therefore, essential to a full understanding of its effects.

Due to the potentially large impacts of IAP on health and mortality, many governments, non-governmental organizations, and international organizations have begun to devise strategies for reducing indoor air pollution for individuals at the bottom rungs of the energy ladder. One method has been to subsidize cleaner fuel technologies. Encourage the use of kerosene rather than traditional biomass fuels, countries such as Indonesia and Ecuador had policies to subsidize kerosene for cooking for the poor [28]. However, this strategy is often not entirely feasible, and can be very costly. In addition, electric stoves are not practical in areas with low electricity levels, and the access of the poor to electricity varies greatly across countries, with $1.3 \%$ in Tanzania of the rural poor having access to electricity versus $99 \%$ in Mexico [29]. Even with subsidies, Kerosene and LPG/Gas are often too expensive for poor households, and they may have the additional difficulty of being difficult to transfer to rural areas that often lack roads. Additionally, these subsidy programs tend to be quite expensive, in an age when governments are trying to trim already overstretched budgets. For example, in Indonesia's program, although many low income households did switch to kerosene, the large inclusion error in targeting led to high program costs.

A second strategy has been the development, promotion and subsidization of "improved cooking stoves." Improved cooking stoves attempt to use traditional fuels in a more efficient manner and, therefore, do not impose a large cost on poor households. Often including a chimney, they are designed to remove harmful pollutants from the kitchen. Unlike the traditional cooking stove, less soot is produced on the walls surrounding the improved cooking stove, indicating that fewer visible pollutants are being emitted in the air.

The improved cooking stove has become a particularly popular policy prescription. While China is reported to lead in the number of improved stoves installed (at over 35 million), India likely ranks second—distributing over 12 million improved stoves in the first seven years of a national program to develop and subsidize improved stoves that has now been ongoing for more than 20 years. Through joint government, donor, and NGO effort, Kenya distributed around 1.5 million jiko stoves (over twenty years), and Ethiopia distributed a similar number of lakech charcoal stoves (over ten years). However, only recently has there been research on whether or not distributing the improved cooking stoves actually is a cost-effective method to both reduce IAP and improve health.

Much of the research has centered on whether the stoves reduce IAP. For example, [15] [30]-[32] have all found that various types of improved cooking stoves have resulted in reductions of toxic pollutants. However, even if they reduce smoke in the households, the effects could, in theory, be mitigated by behavioral responses. First, the stove's ability to reduce smoke relies on its proper use and maintenance. Second, while the improved cooking stove only reduces IAP, it does not remove the smoke from the kitchen entirely. If there is less smoke near the stove, individuals may choose to spend more time around the stove than they previously did. If smoke is indeed greater in the vicinity of the stove than elsewhere in the kitchen, it is then not necessarily clear that an individual who spends more time near the improved cooking stove would suffer from significantly less smoke exposure. Thus, very little understanding of the impact of stoves on health and even less understanding of whether or not the money spent on the stoves could be spent on other, more cost effective health interventions, including alternative interventions to reduce indoor air pollution 


\section{Results}

Agriculture is the main economic activity in the study area, with $100 \%$ of the respondents reporting their main occupation was farming.

Most (36\%) households in the study area consisted of 5 people. This is followed by households with 4 people (30\%), 6 people (16\%), 3 people (14\%) and 7 people (4\%) respectively. The average number of people per household was 5 persons per household.

Forty six (46\%) of household in the study area had 2 children between the ages of 1 and 5 years, while 34\% of households had 3 children between the ages of 1 and 5 years. Only 20\% of households have a single child between the ages of 1 and 5 years. The average number of children aged between 1 - 5 years in the study area was 2 children per household.

Most households in the area of study comprised of 2 houses, constituting 50\%, followed by households with a single house which constituted $42 \%$ and households with 3 houses which constituted $8 \%$.

Majority (66\%), of houses in the area of study were semi-permanent followed by traditional African houses which constituted $24 \%$ and permanent houses which constituted $10 \%$.

Houses with single rooms were predominant in the study area constituting $42 \%$. These were followed by houses with two rooms at 36\%, houses with three rooms at $14 \%$ and houses with four rooms at $8 \%$. Forty eight percent (48\%) of households had fair ventilation; this was closely followed by households with poor ventilation which constituted $40 \%$ and poorly ventilated houses with $12 \%$.

One hundred per cent (100\%) of respondents in the study area use biomass fuel (firewood) for cooking and heating. Affordability and availability of the biomass fuel were identified as the main reasons for using biomass fuel. A majority of the respondents identified affordability as the reason for using biomass fuel while $92 \%$ of the respondents identified availability as a reason for using the biomass fuel. Respondents reported spending between one and two hours per day looking for BMF, 88\% of the respondents reported they spend one hour a day looking for BMF while $12 \%$ of the respondents reported they spend 2 hours a day looking for BMF.

Physical exhaustion was reported as the principle problem in the collection of BMF which constituted $86 \%$. This was followed by bruises (84\%), blisters (30\%) and insect bites at $12 \%$. Majority of the respondents (62\%) reported using the axe for chopping the firewood. This was followed use of the machete (34\%) and power saw (4\%) respectively.

One hundred (100\%) of the respondents reported drying the BMF before using it with $100 \%$ of the respondents reported experiencing problems while processing the BMF while Physical exhaustion (100\%) was reported as the principal problem experienced while processing the BMF. This was followed by blisters and cuts at $34 \%$ and $16 \%$ respectively.

Human powered transportation was used by the respondents to convey the BMF from point of collection to their homes. Majority of the respondents transport the BMF on their head with $92 \%$ of the respondents acknowledging this. $8 \%$ of the respondents reported they transported the BMF on their back. 100\% of the respondents reported they experienced problems while using BMF. Coughing and irritation of the mucus membrane (eye, nose and throat) was reported as the principal problems experienced when cooking with 100\% of respondents attesting to both coughing and irritation of the mucus membrane. These were followed by burns (42\%), shortness of breath (38\%), drowsiness (8\%) and exacerbation of asthma (2\%).

Sixty-six percent (66\%) of households attested to children sleeping in the kitchen area while in 34\% children did not sleep in the kitchen area.

Physical exhaustion was reported as the major problem experienced during conveying of the BMF which constituted $86 \%$. This was followed by neck aches at $78 \%$, headaches at $34 \%$, knee aches at $30 \%$ and back aches at $16 \%$, as explained in Figure 1.

Coughing and irritation of the mucus membrane (eye, nose and throat) was reported as the principal problems experienced when cooking with $100 \%$ of respondents attesting to both coughing and irritation of the mucus membrane. These were followed by burns (42\%), shortness of breath (38\%), drowsiness (8\%) and exacerbation of asthma (2\%), see Figure 2.

\section{Discussion}

Biomass fuel is the predominant fuel type in the study area with $100 \%$ of the respondents acknowledging this. This finding concurs with [4] which revealed up to 95\% of energy consumed in rural areas is in the form BMF. 


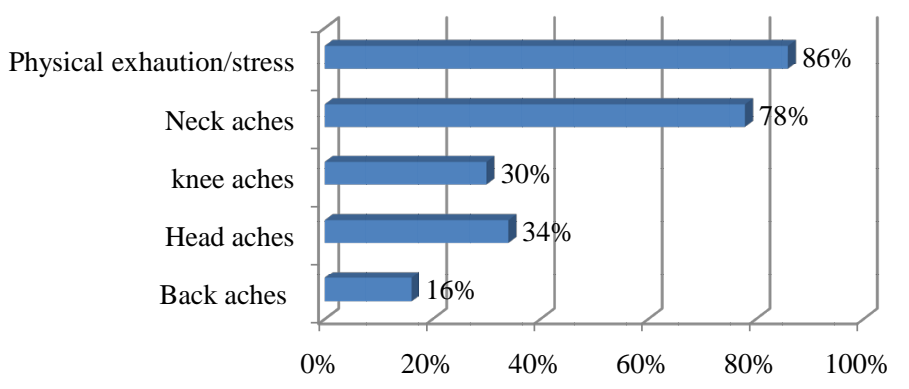

Figure 1. Problems experienced as a result of conveying BMF.

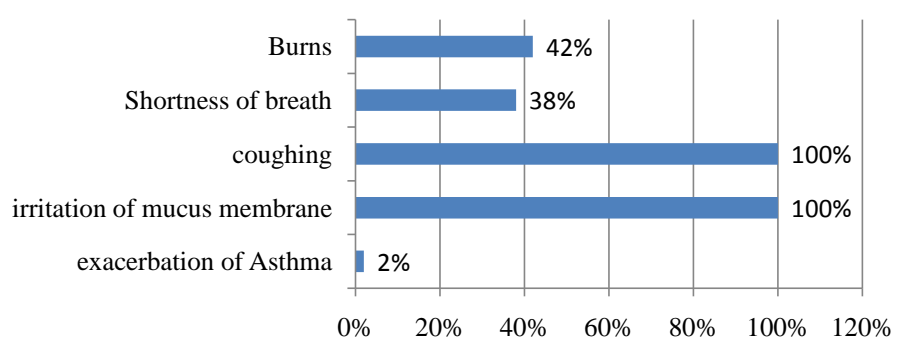

Figure 2. Problems experienced while cooking.

The study area is densely populated by trees thus the ready availability of BMF. Many households in the area of study comprise of single room houses (42\%). These are likely to be overcrowded given an average of five people per household in the study area. These households have an average of two children aged between 1 - 5 years, who in most cases stay around the home environment, since they are not of school age. They stay indoors at mealtime during daytime and at night when open fires have to be lit for cooking or heating. During the wet and cold season, they also spend their time indoors. This increases their exposure to indoor pollutants and thus predisposing them to health problems related to indoor air pollution. These findings concur with previous studies which have proven substandard housing, overcrowding and poor ventilation to exacerbate health problems associated to indoor air pollution [1] [33]. A study by UNICEF revealed a greater prevalence of Acute Respiratory Infections in crowded households where large families inhabit small living space and use biomass fuels in Central province of Kenya, and especially during cold conditions [33].

Many of the sampled houses (48\%) had fair ventilation, while $40 \%$ of the houses had poor ventilation and $12 \%$ had good ventilation. The poorly ventilated houses were characterized by lack of chimneys and had small windows which could not adequately expel the smoke produced from combustion of BMF. The poorly ventilated houses were characterized by presence of soot on the walls in the kitchen area. Although the fairly ventilated houses lacked chimneys they had windows of ample space to expel most of the smoke. In these houses the sooting on the walls was limited to the wall adjacent the traditional open fire. These findings concur with [17] study which stated that kitchen location, ventilation and permeability of walls significantly affect smoke exposure. Studies have shown, indoor smoke in poorly ventilated houses can exceed acceptable levels for small particles in outdoor air by 100 fold [34]. The most important substances that may damage health include carbon (ii) oxide, nitrogen (iv) oxide, sulphur (iv) oxide formaldehyde and volatile organic compounds including carcinogens such as benzene [35]. Particles with diameters below 10 microns, and particularly those less than 2.5 microns in diameter can penetrate deeply into the lung and appear to have the greatest potential for damaging health [5].

Thirty eight per cent (38\%) of the respondents reported experiencing shortness of breath as a problem experienced while cooking using BMF. This is attributed to carbon (ii) oxide produced during combustion of BMF. The CO when inhaled passes through the lungs and absorbed directly into blood stream where it combines with hemoglobin forming carboxyhemoglobin (COHb). The affinity of $\mathrm{COHb}$ for hemoglobin is 210 times greater than that of oxygen and as a result the amount of hemoglobin available for carrying oxygen to body tissue is considerably reduced. This is called carbon monoxide poisoning and is fatal if large amounts of CO are inhaled [36].

Coughing and irritation of the mucus membrane (eye, nose and throat) was reported as the principal problems 
experienced when cooking with $100 \%$ of respondents attesting to both coughing and irritation of the mucus membrane. This is attributed to oxides of sulfur and nitrogen. Sulfur (iv) oxide $\left(\mathrm{SO}_{2}\right)$ has been known to aggravate existing respiratory diseases in humans and to contribute to their development. Even healthy individuals have been known to experience broncho-constriction when exposed for a few minutes to levels of $1.6 \mathrm{ppm}$. Sulfur (iv) oxide is highly soluble in water and causes extreme irritation of the eyes and upper respiratory tract [36].

BMF is the predominant fuel type in the area with $100 \%$ of the respondents using the BMF for cooking and heating. This concurs with finding by UNIDO where the revealed up to 95\% of energy consumed in rural areas is in the form of wood, agriculture residue and animal waste [4]. The study area is densely populated by trees thus the ready availability of BMF. The main economic activity is farming with $100 \%$ of the respondents partaking in farming, thus the ready availability of crop residue such as maize cobs and tea branches to supplement firewood from trees.

Women are particularly vulnerable to the health effects of indoor air pollution as they spend a considerable amount of time near the traditional open fires. This revealed that majority of the women (72\%) are not aware of the negative health effects of IAP. The research also revealed that women suffer different type of physical ailments due to BMF. These results concur with [6] who described how the biomass fuel cycle imposes hardship, stress and physical discomfort for women. Infants and young children are very susceptible to the effects of indoor air pollution. This is because they spend a considerable amount of time near the traditional open fires while their mother is cooking thus increasing their exposure to IAP. During the rainy season the children also spend most of their time indoors near the traditional open fires in an effort to keep warm [37]. The infants and young children have a higher resting metabolic rate and rate of oxygen consumption per unit body weight than adults because they have a larger surface area per unit body weight and because they are growing rapidly. Therefore, their exposure to any air pollutant may be greater. In addition to an increased need for oxygen relative to their size, children have narrower airways than adults. Thus, irritation cause by air pollution that would produce only a slight response in an adult can result in potentially significant obstruction in the air way of a young child [34]. Of great significance are $66 \%$ of the households which attested to children sleeping in the kitchen area, thus exposing them to high levels of the pollutants.

\section{Conclusions}

Cooking with biomass fuel exposes women to harmful indoor air pollution health effects as indicated by other studies [3]. However, other health impacts are experienced during the various stages of the biomass fuel chain.

- Gathering

Physical exhaustion/stress, bruises, blisters and insect bites were reported as the principal health effect associated with the first stage of the biomass fuel chain.

- Processing

Physical exhaustion, blisters and cuts were reported as the principal health effects associated with the second stage of the biomass fuel chain.

- Transportation

Physical exhaustion, neck aches, headaches, knee aches, and back aches were reported as the principal health effects associated with the third stage of the biomass fuel chain.

- Cooking

Irritation of the mucus membrane of the eyes, nose, throat, coughing, burns, shortness of breath and exacerbation of asthma were identified as principal health effects associated with the fourth stage of the biomass fuel chain, which was cooking.

Availability and affordability of the biomass fuel were identified as the main factors promoting the use of BMF in the study area with $96 \%$ of the respondents attesting to affordability and $92 \%$ attesting to availability of the biomass fuel.

\section{Recommendation}

As a result of the detrimental impact of IAP on health and mortality, many governments, non-governmental organization and international organizations should develop strategies aimed at reducing indoor air pollution.

1) Subsidization of cleaner fuel technologies, like kerosene and LPG/gas rather than traditional biomass fuels.

2) Use of solar thermal cookers and solar hot water heaters. 
3) Processing biomass fuel to make them cleaner.

4) Modifying user behavior plays a role in reducing exposure to indoor smoke. Drying fuel wood before use improves combustion and lowers smoke production while using lids on pots, reduces cooking time.

5) Improve household design.

\section{References}

[1] Smith-Sivertsen, T., Díaz, E., Bruce, N., Díaz, A., Khalakdina, A., Schei, M., McCracken, J., Arana, B., Klein, R., Thompson, L., and Smith K. (2004) Reducing Indoor Air Pollution with a Randomized Intervention Design-A Presentation of the Stove Intervention Study in the Guatemalan Highlands. Norsk Epidemiologi, 14, 137-143.

[2] International Energy Agency (2010) World Energy Outlook. IEA, Paris. www.se4all.org/wpcontent/uploads/2013/09/special_Excerpt_of_WEO_2010.p.wse

[3] WHO (2004) The world Health Report 2004: The Changing History. Geneva.

[4] Environmental Protection Agency (1997) Revisions to the National Ambient Air Quality Standards for Particles Matter. Federal Register, 62, 38651-38701.

[5] Wickramasinghe, A. (2001) Gendered Sights and Healthy Issues in the Paradigm of Bio-Fuel in SriLanka. ENERGIANews, 4, 12-14.

[6] Dara, M. (2001) Health Implications for Women and Children of Wood Fuel Use in Cambodia. ENERGIA News, 4, 14-15.

[7] Laxmi, V., Parikh, J., Karmakar, S. and Dabrase, P. (2003) Household Energy, Women’s Hardship and Health Impacts in Rural Rajasthan, India: Need for Sustainable Energy Solutions. Energy for Sustainable Development, 7, 50-68. http://dx.doi.org/10.1016/S0973-0826(08)60348-8

[8] Wallace (1989) Major sources of Benzene exposure. Environmental Health Perspective, 82, 165-169.

[9] EPA (1990) Air Pollution and the Clean Air Act. EPA, Washington DC. http://www.epa.gov/cleanairactbenefits

[10] WHO (1987) Styrene. In: Air Quality Guidelines for Europe. WHO Regional Publications, European Series No. 23, Copenhagen, 118-126.

[11] Hoskins, J.A. (2011) Health Effects Due to Indoor Air Pollution. Environmental Earth Sciences, 2011, 665-676.

[12] Mohan, M., Sperduto, R.D., Angra, S.K., Milton, R.C., Mathur, R.L. and Underwood, B.A. (1989) India-US CaseControl Study of Age-Related Cataracts. Archives of Ophthalmology, 107, 670-676. http://dx.doi.org/10.1001/archopht.1989.01070010688028

[13] Thomas, P. and Zelikoff, J. (1999) Air Pollutants: Moderators of Pulmonary Host Resistance against Infection. In: Holgate, S.T., Samet, J.M., Koren, H.S. and Maynard, R.L., Eds., Air Pollution and Health, Academic Press, San Diego, 357-379. http://dx.doi.org/10.1016/B978-012352335-8/50092-2

[14] Ezzati, M. and Kammen, D. (2001) Indoor Air Pollution from Biomass Combustion and Acute Respiratory Infections in Kenya: An Exposure-Response Study. The Lancet, 358, 619-624. http://dx.doi.org/10.1016/S0140-6736(01)05777-4

[15] WHO (2002) Addressing the Links between Indoor Air Pollution, Household Energy and Human Health. Based on the WHO-USAID Global Consultation on the Health Impact of Indoor Air Pollution and Household Energy in Developing Countries (Meeting Report), Washington DC, 3-4 May 2000.

[16] Dasgupta, S., Huq, M., Khaliquzzaman, M., Pandey, K. and Wheeler, D. (2004) Who Suffers from Indoor Air Pollution? Evidence from Bangladesh. World Bank Policy Research Working Paper 3428.

[17] Duflo, E., Greenstone, M. and Hanna, R. (2008) Indoor Air Pollution, Health and Economic Well-Being. Surveys and Perspective Integrating Environment and Society (EPIENS), 1, 1

[18] Bruce, N., Rehfuess, E., Mehta, S., Hutton, G. and Smith, K. (2006) Indoor Air Pollution. In: Jamison, D.T., Breman, J.G., Measham, A.R., Alleyne, G., Claeson, M., Evans, D.B., Jha, P., Mills, A. and Musgrove, P., Eds., Disease Control Priorities in Developing Countries, 2nd Edition, Oxford University Press, New York, 793-815.

[19] Pitt, M., Rosenzweig, M. and Hassan, N. (2006) Sharing the Burden of Disease: Gender, the Household Division of Labor and the Health Effects of Indoor Air Pollution. Mimeo.

[20] Strauss, J. and Thomas, D. (1998) Health, Nutrition, and Economic Development. Journal of Economic Literature, 36, 766-817.

[21] EPA: Environmental Protection Agency (2006) Particulate Matter Standards. US Environmental Protection Agency. www.epa.gov/airscience/air-particulatematter.htm

[22] Smith, K.R. (1999) The National Burden of Disease from Indoor Air Pollution in India. In: Raw, G., Aizlewood, C. and Warren, P., Eds., Indoor Air 99, the 8th International Conference on Indoor Air Quality and Climate, Construction 
Research Ltd., Edinburgh, 13-18.

[23] Zhang, J. and Smith, K.R. (2007) Household Air Pollution from Coal and Biomass Fuels in China: Measurements, Health Impacts, and Interventions. Environmental Health Perspective, 115, 848-855. http://dx.doi.org/10.1289/ehp.9479

[24] Zhang, J. and Smith, K.R. (2005) Indoor Air Pollution from Household Fuel Combustion in China: A Review. The 10th International Conference on Indoor Air Quality and Climate, Beijing, 4-9 September 2005, 8-10.

[25] Menon, P. (1988) Indoor Spatial Monitoring of Combustion Generated Pollutants (TSP, CO, and Bap) by Indian Cookstoves. Rep. UHMET 88-01. Dep. Meteorol., University of Hawaii, Honolulu.

[26] Saksena, S., Prasad, R., Pal, R.C. and Joshi, V. (1992) Patterns of Daily Exposure to TSP and CO in the Garhwal Himalaya. Atmospheric Environment. Part A. General Topics, 26, 2125-2134. http://dx.doi.org/10.1016/0960-1686(92)90096-4

[27] Banres, D, and Halpern, J. (2000) The Role of Energy Subsidies. Chapter 7, Energy and Development Report 2000: Energy Services for the World's Poor, World Bank.

[28] Duflo, E., Greenstone, M. and Hanna, R. (2007) Cooking Stoves, Indoor Air Pollution, and Respiratory Health in Orissa, India. Mimeo.

[29] McCracken, J.P. and Smith, K.R. (1998) Emissions and Efficiency of Improved Wood Burning Cook Stoves in Highland Guatemala. Environment International, 24, 739-747. http://dx.doi.org/10.1016/S0160-4120(98)00062-2

[30] Ezzati, M., Saleh, H. and Kamman, D. (2000) The Contributions of Emissions and Spatial Microenvironments to Exposure to Indoor Air Pollution from Biomass Combustion in Kenya. Environmental Health Perspectives, 108, 833-839.

[31] Ezzati, M., Mbinda, M.B. and Kammen, D.M. (2000) Comparison of Emissions and Residential Exposure from Traditional and Improved Cook Stoves in Kenya. Environmental Science and Technology, 34, 578-583. http://dx.doi.org/10.1021/es9905795

[32] Albalak, R., Bruce, N., McCracken, J.P., Smith, K.R. and de Gallardo, T. (2001) Indoor Respirable Particulate Matter Concentrations from an Open Fire, Improved Cook-Stove, and LPG/Open Fire Combination in a Rural Guatemalan Community. Environmental Science and Technology, 35, 2650-2655. http://dx.doi.org/10.1021/es001940m

[33] United Nation Children's Fund (1998) A Situation Analysis for Children and Women in Kenya. Nairobi.

[34] WHO (2005) Indoor Air Pollution and Health. Fact Sheet, No. 292. Children’s Health and the Environment. A Global Perspective. A Resource Guide for the Health Sector.

[35] Smith, K.R., De Koning, H.W. and Last, J.M. (1985) Biomass Fuel Combustion and Health. Bulletin of the World Health Organization, 63, 11-26.

[36] Rao, C. (1991) Environmental Pollution Control Engineering: New Age international publisher. 55-68.

[37] Moya, J., Bearer, C. and Etzel, R. (2004) Children’s Behavior and Physiology and How It Affects Exposure to Environmental Contaminants. Pediatrics, 113, 996. 
Scientific Research Publishing (SCIRP) is one of the largest Open Access journal publishers. It is currently publishing more than 200 open access, online, peer-reviewed journals covering a wide range of academic disciplines. SCIRP serves the worldwide academic communities and contributes to the progress and application of science with its publication.

Other selected journals from SCIRP are listed as below. Submit your manuscript to us via either submit@scirp.org or Online Submission Portal.
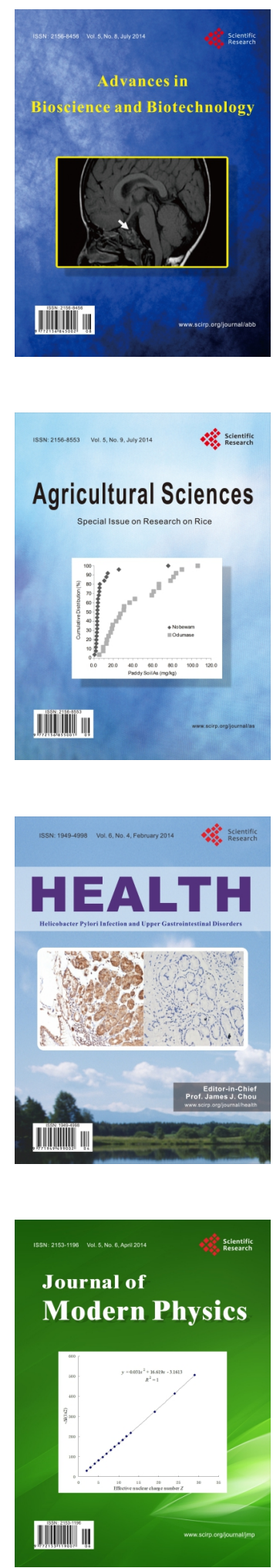
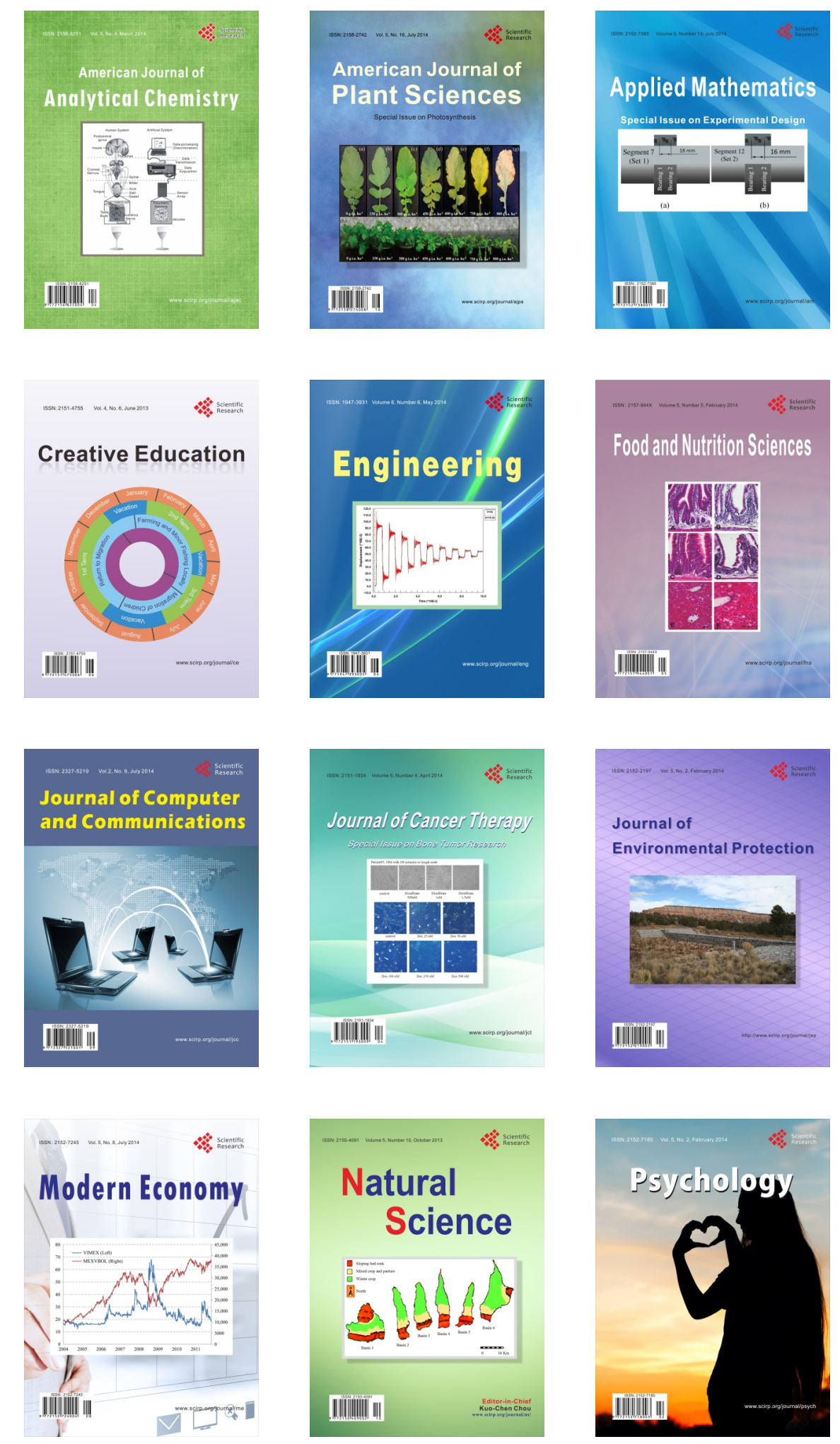